Article - Discoveries

\title{
Evolutionary dynamics of sex-biased gene expression in a young XY system: Insights from the brown algae
}

\author{
William J. Hatchett ${ }^{1}$, Alexander Jueterbock ${ }^{1}$, Martina Kopp ${ }^{1}$, James A. Coyer ${ }^{3}$, Susana M. Coelho ${ }^{2,4}$, \\ Galice Hoarau ${ }^{1}$, Agnieszka P. Lipinska ${ }^{2,4 \#}$ \\ ${ }^{1}$ Faculty of Biosciences and Aquaculture, Nord University, Bodø, Norway \\ ${ }^{2}$ Sorbonne Université, CNRS, Algal Genetics Group, UMR 8227, Integrative Biology of Marine Models, \\ Station Biologique de Roscoff, Roscoff, France \\ ${ }^{3}$ School of Marine Science and Ocean Engineering, University of New Hampshire, Durham, USA \\ ${ }^{4}$ Department of Algal Development and Evolution, Max Planck Institute for Developmental Biology, \\ Tuebingen, Germany
}

\#Corresponding author;

Keywords: sexual dimorphism, sex biased genes, brown algae, $X Y$ sex chromosomes

\section{ABSTRACT}

The sex-dependent regulation of gene expression is considered to be the underlying cause of often extensive, sexually dimorphic traits between males and females. Although the nature and degree of sex-biased gene expression has been well-documented in several animal and plant systems, far less is known about the commonality, conservation, recruitment mechanisms and evolution of sex-biased genes in more distant eukaryotic groups. Brown algae are of particular interest for empirical studies on the evolution of sex-biased gene expression, as they have been evolving independently from animals and plants for over one billion years. Here we focus on two brown algal dioecious species, Fucus serratus and Fucus vesiculosus, where male heterogamety (XX/XY) has recently emerged. Using RNA-seq, we study sex-biased gene expression and discuss different evolutionary forces responsible for the evolution of sex-biased genes. We find that both species evolved masculinized transcriptomes, with sex-biased genes allocated mainly to male reproductive tissue, but virtually absent in vegetative tissues. Conserved male-biased genes were enriched in functions related to gamete production, along with sperm competition and include two flagellar proteins under positive selection. In contrast to female-biased genes, which show high turnover rates, male-biased genes reveal remarkable conservation of bias and expression levels between the two species. As observed in other XY systems, male-biased genes also display accelerated rates of coding sequence evolution compared to female-biased or unbiased genes. Our results imply that evolutionary forces affect male and female sex-biased genes differently on structural and regulatory levels. Similarly to evolutionary 
bioRxiv preprint doi: https://doi.org/10.1101/2021.08.12.455804; this version posted August 15, 2021. The copyright holder for this preprint (which was not certified by peer review) is the author/funder, who has granted bioRxiv a license to display the preprint in perpetuity. It is made available under aCC-BY-NC-ND 4.0 International license.

distant plant and animal lineages, sex-biased gene expression in Fucus evolved during the transition to dioecy to resolve intra-locus sexual conflict arising from anisogamy.

\section{INTRODUCTION}

Males and females can display striking differences in morphology, physiology and behavior. Evolution of these sexually dimorphic traits is thought to be rooted in anisogamy and shaped by sex-specific selection (Hedrick and Temeles 1989; Connallon and Knowles 2005; Ellegren and Parsch 2007; Schärer et al. 2012). Ultimately, the sexes are defined by the gamete size they produce (either many small or fewer larger gametes) and sexual selection is predicted to act differently with regard to these two distinct reproductive strategies (Kokko and Jennions 2008; Schärer et al. 2012). Due to the disparity of resources and energy invested by males and females in their reproductive cells, it is hypothesized that sexual selection will be stronger in the sex that makes the smaller, more abundant and relatively 'cheaper' to produce gametes, resulting in male-biased sexual dimorphism (Darwin 1871; Bateman 1948; Parker 1979; Schärer et al. 2012; Andersson 2019). Because males and females share the majority of their genomic sequence, the expression of sexually dimorphic traits rely largely on the regulation of sex-biased gene expression (SBG) (Ellegren and Parsch 2007; Parsch and Ellegren 2013; Grath and Parsch 2016). Sex-biased expression allows males and females to avoid the constraints of a shared genome and to cope with intralocus conflict arising from sexually antagonistic selection (RICE 1998; Connallon and Knowles 2005; Ellegren and Parsch 2007; Cox and Calsbeek 2009; Parsch and Ellegren 2013).

Sex-biased gene expression has been well documented across a wide number of animal species such as insects (Zha et al. 2009; Perry et al. 2014; Papa et al. 2017), mammals (Yang et al. 2006; Blekhman et al. 2010; Naqvi et al. 2019), birds (Mank et al. 2007; Mank and Ellegren 2009; Harrison et al. 2015), and recently also in plants (Zemp et al. 2016; Darolti et al. 2018; Cossard et al. 2019) and brown algae (Martins et al. 2013; Lipinska et al. 2015; Monteiro et al. 2019; Müller et al. 2021). It has been shown that SBG expression can vary in strength throughout development, can be detected already at juvenile stages (Thoemke et al. 2005; Magnusson et al. 2011; Ingleby et al. 2014; Perry et al. 2014), and can constitute a large proportion of the transcriptome, with up to $90 \%$ in extreme cases (Ranz et al. 2003; Ayroles et al. 2009). Genome-wide expression studies have found that sex-biased genes tend to be more abundant in males (known as a masculinised transcriptome), where they show stronger bias and more rapid turnover rates compared to female-biased genes (Parisi et al. 2003; Ranz et al. 2003; Yang et al. 2006; Voolstra et al. 2007; Martins et al. 2013; Parsch and Ellegren 2013; Harrison et al. 2015; Yang et al. 2016). Apart from faster evolution of the gene expression levels, male-biased genes more often experienced higher divergence rates of protein-coding sequences than female biased or unbiased genes, at least partially, attributed to stronger positive selection (Zhang et al. 2004a; Grath and Parsch 2012; Allen et al. 2018; Cutter 2018, Connallon and Knowles 
bioRxiv preprint doi: https://doi.org/10.1101/2021.08.12.455804; this version posted August 15, 2021. The copyright holder for this preprint (which was not certified by peer review) is the author/funder, who has granted bioRxiv a license to display the preprint in perpetuity. It is made available under aCC-BY-NC-ND 4.0 International license.

2005; Ellegren and Parsch 2007; Mank and Ellegren 2009; Parsch and Ellegren 2013). In contrast, female-biased genes often evolve at similar or slower rates compared with unbiased genes possibly due to larger pleiotropic constraints (Ellegren and Parsch 2007; Zhang et al. 2007; Assis et al. 2012). Altogether, these observations suggest that male traits experience stronger sexual selection and sexual conflict arising from anisogamy (Ranz et al. 2003; Connallon and Knowles 2005; Hayward and Gillooly 2011; Janicke et al. 2016). However, our knowledge about the evolution of sex-biased expression is limited, mainly, to the animal species with conspicuous sexual dimorphism, where separate sexes evolved long time ago.

Here, we study the evolution of sex-biased gene expression in two brown algal species from the order Fucales which recently evolved separate sexes (Serrão et al. 1999; Coyer et al. 2006; Heesch et al. 2021). Brown algae constitute an interesting group to study the evolution of sexual systems and sex-biased expression because they have been evolving independently of organisms such as animals, fungi and plants for over a billion years (Baldauf 2003). The majority of brown algal species engage in a haploid-diploid life cycle where sex is expressed during the haploid gametophyte generation and controlled by haploid sex chromosomes (UV system) (Coelho et al. 2018). In that respect, Fucales are unique among the brown algae as they represent the only group that underwent a recent shift towards a diplontic life history, in which the short-lived male sperm and female egg are the only haploid stages (Coelho et al. 2019). Moreover, the conversion to diploidy imposed a switch to the diploid sex-determination system from the haploid UV (via a hermaphroditic intermediate) in several families of Fucales around 17.5 Mya (Heesch et al. 2021). While the transition to diploid sex determination from the haploid system seems to be irreversible, further transitions towards hermaphroditism within the diploid lineages are still possible and occurred independently in several genera of the Fucaceae (Heesch et al. 2021).

Fucus species have a rather simple structure with the vegetative body being made up of a holdfast, a thallus and the fronds. The fronds contain reproductive receptacles which in dioecious species bear either antheridia (producing motile sperm) or oogonia (producing immotile, large eggs) (Serrão et al. 1999; Coyer et al. 2006; Cánovas et al. 2011; Hoarau et al. 2015) (Fig. 1). The eggs produce pheromones which facilitate gamete-gamete recognition by attracting sperm within a very short distance (Müller and Gassmann 1985) and fertilized zygotes usually settle within one to two meters of the parent (Arrontes 1993; Serrão et al. 1997). The different reproductive structures are the only visible sexually dimorphic trait in Fucus in the absence of detailed morphometric measures, so that dioicous species are sexed solely by the presence of male or female gametes (Coyer et al. 2002). We focused on dioecious species of, two distinct lineages, Fucus serratus (Lineage 1) and Fucus vesiculosus (Lineage 2), that dominate the rocky intertidal North Atlantic shoreline. The two lineages evolved around 0.9 to 2.25 Mya and both contain hermaphroditic species, including Fucus distichus (Lineage 1) and Fucus spiralis (Lineage 2) (Serrão et al. 1999; Coyer et al. 2006; Hoarau et al. 2007). 
All four species often occur intertwined with one another and molecular studies have shown that hybridization is common, involving dioecious-hermaphrodite species pairs within each lineage, but hybrids of dioecious species are almost never found (Coyer et al. 2002; Wallace et al. 2004; Billard et al. 2005; Coyer et al. 2007; Hoarau et al. 2015). Ancestral state reconstruction analysis suggested dioecy as the most likely ancestral sexual system in the Fucus genus, however, the direction of transition between co-sexuality and separate sexes within Lineage 1 and 2 remains ambiguous (Heesch et al. 2021).

Field observations and laboratory crosses of Fucus serratus-Fucus distichus hybrids, allowed the identification of the type of sexual system in dioecious species as a male heterogamety $(X X / X Y)$ (Coyer et al. 2002). Combined with the low levels of selfing, almost $100 \%$ fertilization success in dioecious species and effective polyspermy block (Bolwell et al. 1977; Brawley 1992; Pearson and Brawley 1996; Serrao et al. 1996; Coyer et al. 2002), these observations suggest that the targets of reinforcement and speciation in Fucus involve the gamete attraction and/or recognition genes. Moreover, high levels of sperm competition in marine free spawners like Fucus imply there is strong selection pressure on the males for reproductive success as species in sympatry have increased sperm specificity (Hoarau et al. 2015).

In this work, we explore male and female transcriptomic data of Fucus serratus and Fucus vesiculosus which recently evolved dioecy, to perceive the early stages of the evolution of sex biased gene expression. We study evolutionary dynamics of sex-biased transcriptome expression, investigate the conservation of gene expression patterns between the two algal species and identify sex-biased genes with signatures of positive selection in this relatively young XX/XY system. 


\section{RESULTS}

\section{Transcriptome assembly and analysis of gene expression}

We sequenced reproductive and vegetative tissue from males and females of dioecious F. serratus and $F$. vesiculosus. We obtained a total of 478 million reads from two sequencing runs with an average of over 21 million reads per tissue type and species (TableS1). The de novo assembled reference transcriptome for each species contained 29,610 genes for F. vesiculosus and 39,009 genes for F. serratus (Table S1, see "Methods" section for details), after filtering out the transcripts with low expression or high similarity to other transcripts. BUSCO v3 (Waterhouse et al. 2018) estimated completeness of each reference transcriptome at $88.8 \%$ for $F$. vesiculosus and $92.4 \%$ for $F$. serratus (TableS1).

\section{Sex-biased gene expression}

Genes with significant sex-biased expression $\left(F C>=2, p_{\text {adj }}<0.05\right)$ were identified in two comparisons, male reproductive vs female reproductive tissue and male vegetative vs female vegetative tissue, using the DESeq2 R package (Love et al. 2014) (TableS2,S3). As expected, the greater number of sexbiased genes (SBGs) was found in the reproductive tissue when male vs female receptacles were compared (2,993 and 2,772 genes in F. serratus and F. vesiculosus, respectively) (Fig.2A). In contrast, in vegetative tissues, only 20 and 22 genes were found sex-biased in F. serratus and F. vesiculosus, respectively (TableS2,S3). Since the sex-biased genes from the vegetative tissue overlapped largely with those from the reproductive tissue, we decided to focus on the latter in all consecutive analyses on sex-biased gene expression.

We found more male-biased genes (MBGs) than female-biased genes (FBGs) in both species $(2,315$ MBGs vs 678 FBGs in F. serratus; and 2,025 MBGs vs 747 FBGs in F. vesiculosus) (Fig.2A). Noteworthy, more than half of the MBGs were also male-specific (55\% in F. serratus and $58 \%$ in F. vesiculosus), meaning their expression in female reproductive tissue fell below the detection threshold $\left(\log _{2}(T P M+1)<0\right)($ Fig.2A). In contrast, the majority of female-biased genes were also expressed in male receptacles, and female-specific genes constituted a smaller fraction of the female sex-biased gene (FBG) pool (17\%, F. serratus ; 3\%, F. vesiculosus) (Fig.2A) (TableS3).

To further examine the relationship between the expression levels and the degree of sex-bias, we grouped the genes according to the Fold Change $(\mathrm{FC})$ difference between males and females and plotted their mean expression levels in each sex (Fig.2B). In both Fucus species, sex-biased expression resulted from down-regulation of gene expression in the opposite sex rather than up-regulation in the given sex (Fig. 2B). In the genes showing strongest sex-biased expression (FC >20), downregulation resulted from silensing $\left(\log _{2}(T P M+1)<0\right)$ of the given gene in the other sex. Interestingly, between $60-90 \%$ of female-biased genes featured moderate expression bias $(2<\mathrm{FC}<6)(416$ in $\mathrm{F}$. 
bioRxiv preprint doi: https://doi.org/10.1101/2021.08.12.455804; this version posted August 15, 2021. The copyright holder for this preprint (which was not certified by peer review) is the author/funder, who has granted bioRxiv a license to display the preprint in perpetuity. It is made available under aCC-BY-NC-ND 4.0 International license.

serratus; and 674 in F. vesiculosus), whereas the majority of male-biased genes were silent in females and exhibited very high fold changes ( $F C>20)$ ( $61 \%$ or 1,416 genes in F. serratus and $59 \%$ or 1,201 genes in F. vesiculosus) which confers with the high proportion of male-specific SBGs (Fig.2A,B).

A

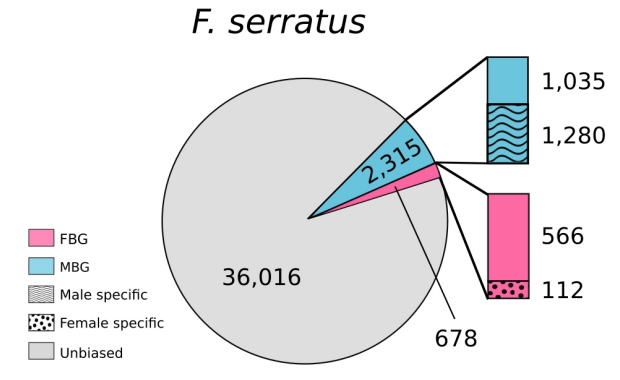

B
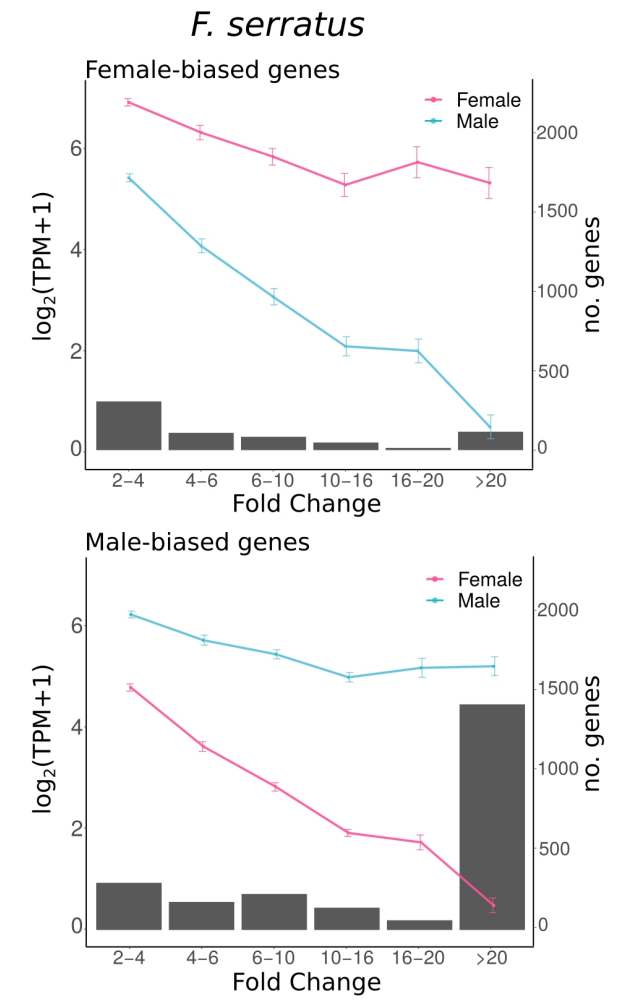

C

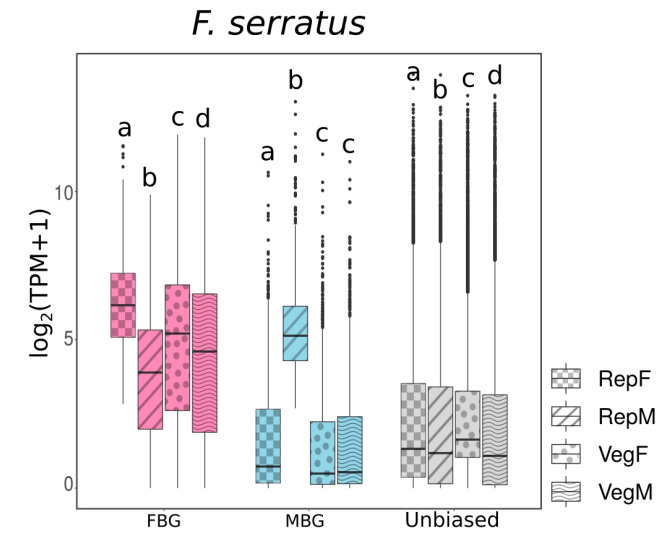

F. vesiculosus

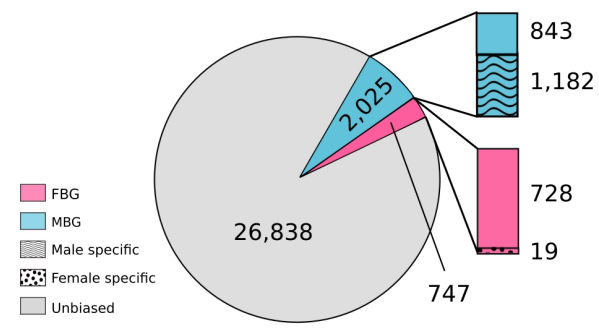

F. vesiculosus
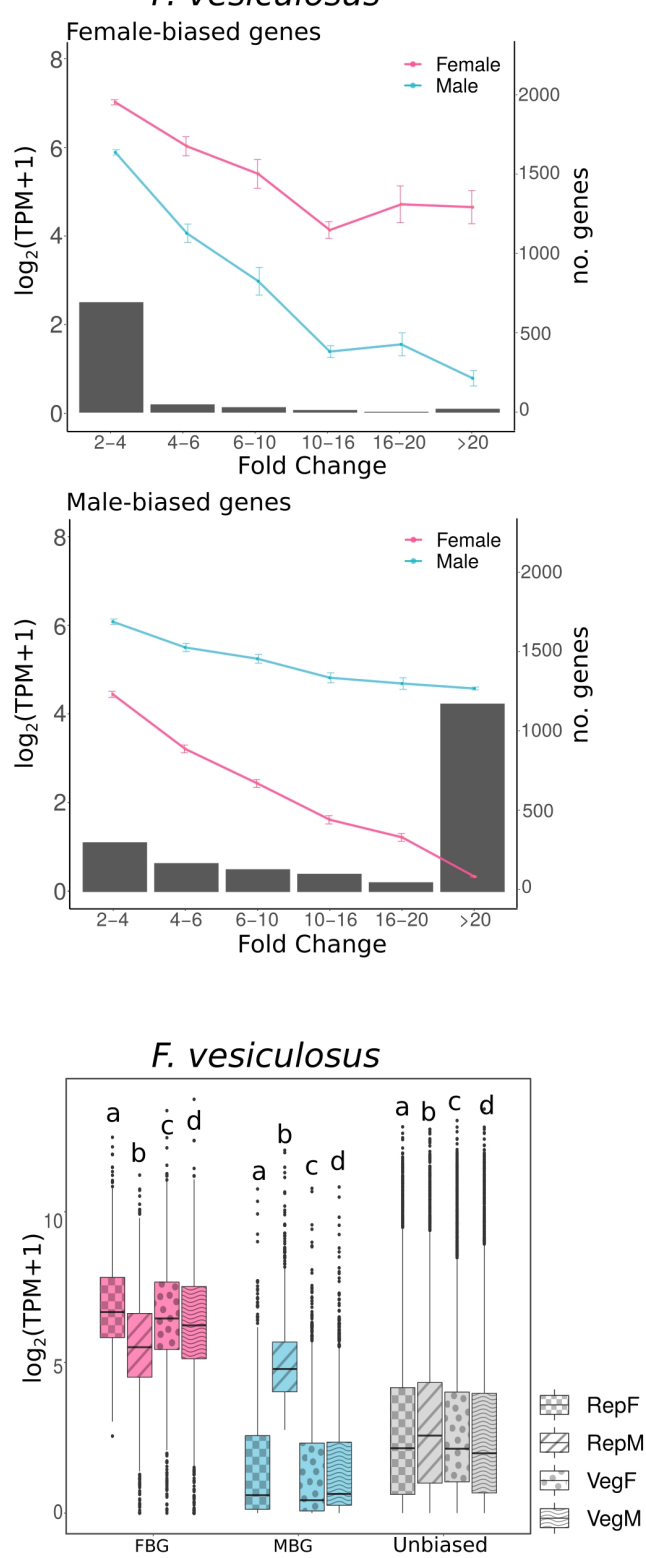

Figure 2. Sex-biased gene expression. A) Number of sex-biased genes (MBG - male-biased and FBG - femalebiased) in $F$. serratus and $F$. vesiculosus reference transcriptomes. Unbiased genes were defined as $p_{\text {adj }}>0.05$ or showing less than 2-fold difference between the sexes. Bars represent the proportion of sex-specific genes among the sex-biased genes in each species. B) Mean expression levels $(\log 2(T P M+1))$ of female-biased and male-biased genes at several degrees of sex-bias (Fold Change) in the female (pink) and male (blue) 
bioRxiv preprint doi: https://doi.org/10.1101/2021.08.12.455804; this version posted August 15, 2021. The copyright holder for this preprint (which was not certified by peer review) is the author/funder, who has granted bioRxiv a license to display the preprint in perpetuity. It is made available under aCC-BY-NC-ND 4.0 International license.

reproductive tissues. Error bars represent standard errors. Bar plot indicates the number of genes in each FC category. C) Boxplot showing the mean expression levels across the replicates (log2(TPM+1)) of female-biased (pink), male-biased (blue) and unbiased (grey) genes in male and female reproductive and vegetative tissues. The letters above the plots indicate significant differences within each gene group (pairwise Wilcoxon test, $\mathrm{p}$ <0.05). RepF -female reproductive tissue; RepM - male reproductive tissue; VegF - female vegetative tissue; VegM - male vegetative tissue.

We also noted that female-biased genes were highly expressed and ubiquitously present in both sexes and both tissue types, including male receptacles (Fig.2C). Conversely, MBGs showed a strong signal of expression only in the male reproductive tissue, and had significantly lower expression levels compared to unbiased genes in male and female vegetative and female reproductive tissues in both species (Fig.2C, p<2e-16 in all pairwise Wilcoxon tests).

\section{Tissue-biased gene expression}

We analyzed transcript abundance in the reproductive versus vegetative tissues within each sex and species to identify genes with tissue-biased expression (FC $\left.>=2, \mathrm{p}_{\mathrm{adj}}<0.05\right)$ (TableS2,S3)(Fig.3A). Males of both Fucus species displayed higher tissue-bias than females, and more of these tissue-biased genes were over-expressed in the reproductive organs compared to vegetative tissue (Fig.3A). To identify sex-biased genes that were predominantly expressed in the reproductive tissue, we compared the tissue-biased data set with that of the male and female sex-biased genes identified above. Not surprisingly, the majority of the male reproductive tissue biased genes overlapped with MBGs ( $72 \%$ and $88 \%$ in F. serratus and F. vesiculosus, respectively), whereas FBGs were more uniformly expressed across the female body (only $18 \%$ and $7 \%$ localized specifically in the reproductive tissue of F. serratus and F. vesiculosus, respectively) (Fig.3A, shaded area). Noteworthy, the SBGs showed significantly higher degrees of sex-bias in the reproductive tissue than in the nonreproductive tissue in both sexes and species (Fig.3B, Wilcoxon test, $\mathrm{p}<1.4 \mathrm{e}-06$ ). 

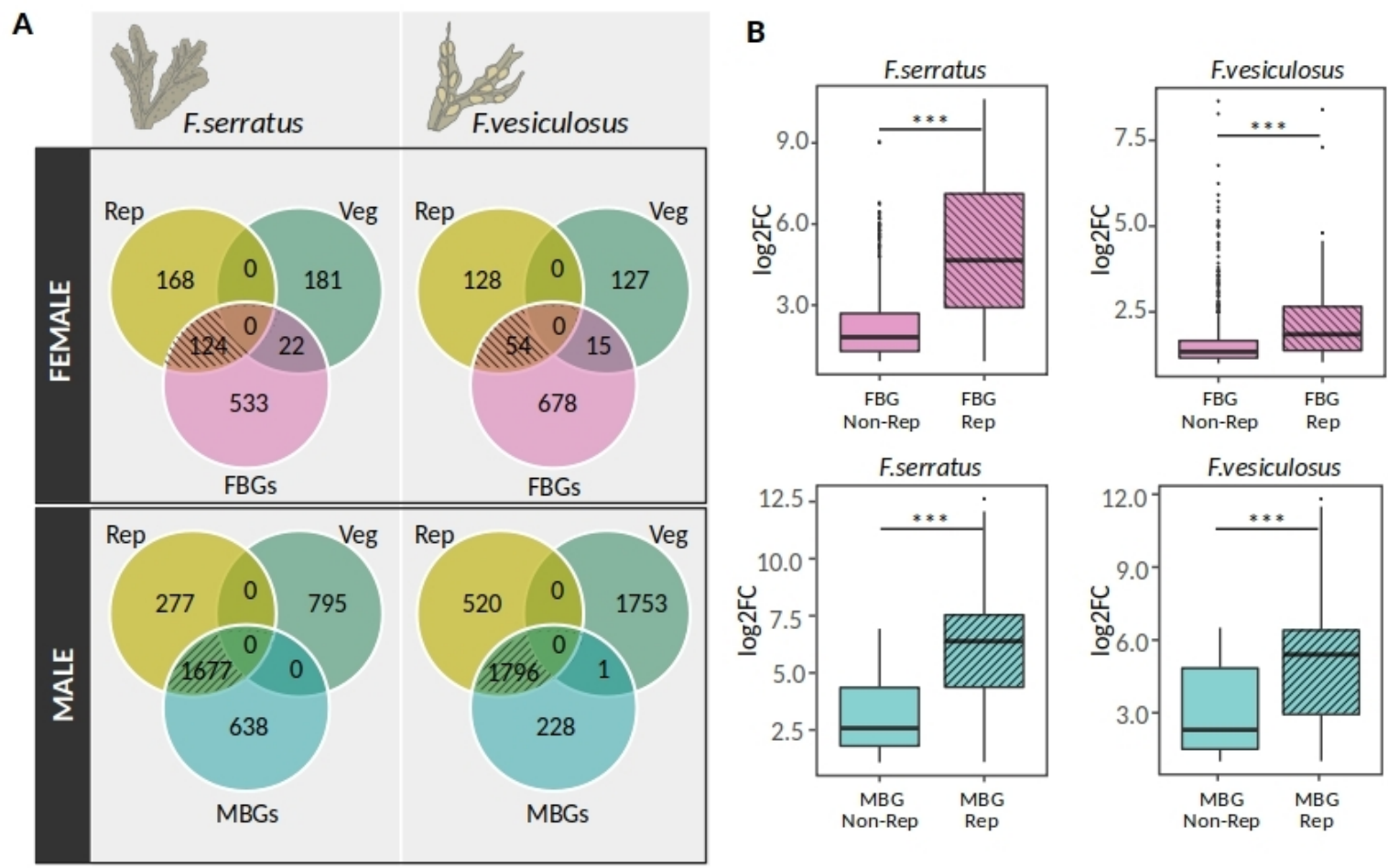

Figure 3. Sex-biased genes (SBGs) over-expressed specifically in the reproductive tissue. A) Venn diagram shows numbers of significantly differentially expressed genes between reproductive (Rep) and vegetative (Veg) tissues of males and females from F. serratus and $F$. vesiculosus (FC $>2$, padj<0.05). The shaded overlap highlights female-biased genes (top) and male-biased genes (bottom) that were over-expressed in reproductive tissue. B) Overall levels of sex-biased expression (log2FC) of SBGs up-regulated in reproductive (Rep) or vegetative tissue (Non-Rep)(Wilcoxon test, $\mathrm{p}<1.4 \mathrm{e}-06$ ).

\section{High conservation of male-biased expression in Fucus.}

Using Orthofinder, we found 20,077 orthogroups that comprised 85,430 genes $(72.6 \%$ of all the genes), out of which 14,818 OGs contained genes from both dioecious species ( $F$. vesiculosus and $F$. serratus). In addition, we searched for single copy orthologs within each lineage (F.distichus - F. serratus, hereinafter Lineage 1, and F.spiralis - F. vesiculosus, hereinafter Lineage 2) as well as between the two dioecious species (F. serratus - F. vesiculosus). We found 9,401 and 8,758 one-toone orthologs in Lineage 1 and Lineage 2 respectively, and 9,778 one-to-one orthologs in the dioecious pair (TableS4). Up to $35 \%$ of genes in each species were "orphans", meaning speciesspecific genes, without any intra- or inter-specific orthologs.

Comparisons of orthogroups comprising the sex-biased genes of F. serratus and F. vesiculosus revealed that the male biased genes were highly conserved between the two species ( TableS4). As much as $65 \%$ to $75 \%$ of the OGs containing male-biased genes were common between F. serratus and F. vesiculosus. In contrast, only $20 \%$ to $26 \%$ of orthogroups with female-biased genes were shared between these species (Fig.4A). Interestingly, the low number of conserved female-biased genes was not caused by the presence of orphan genes among FBGs, but rather gain/loss of female 
bias in existing, orthologous genes. In fact, the proportions of sex-biased genes among the orphan genes were significantly lower than expected in both species and sexes (Chi-square test, $p<2.4 \mathrm{e}-23$, Table.S5). Taken together, we observed high conservation of male sex-biased expression and high turnover of female-biased genes between F. serratus and F. vesiculosus.

To further analyze the conservation of the sex-biased expression, we focused on genes for which there was a clear one-to-one relationship across F. serratus and F. vesiculosus. Out of the 9,778 orthogroups with single copy genes, $21 \%$ (2,070 OGs) contained genes with sex-biased expression in at least one of the two species (TableS4). Again, male sex bias was strongly conserved across the two lineages and applied to roughly $70-80 \%$ of MBGs with one-to-one orthologs, contrary to $25-16 \%$ of conserved FBGs in F. serratus/F. vesiculosus (Fig.4B).

The patterns of expression of conserved and species-specific SBGs showed similar trends in $F$. serratus and F. vesiculosus (Fig.4C). Genes with conserved sex bias had significantly higher average expression levels in reproductive tissue than the species specific SBGs (genes biased towards one sex in on species but not the other) (Fig.4C, Wilcoxon test, $p<0.001$ ). Interestingly, this was also true for the conserved FBGs in the vegetative tissue (Wilcoxon test, $p<0.01$ ), whereas conserved male biased genes exhibited significantly lower expression levels in the vegetative tissue compared to speciesspecific MBGs (Wilcoxon test, $p<0.001$ ). In short, conserved male-biased genes were primarily expressed in reproductive tissue and constituted almost half of the male biased genes found in the receptacles (42\% in F. serratus and $48 \%$ in F. vesiculosus). 
A

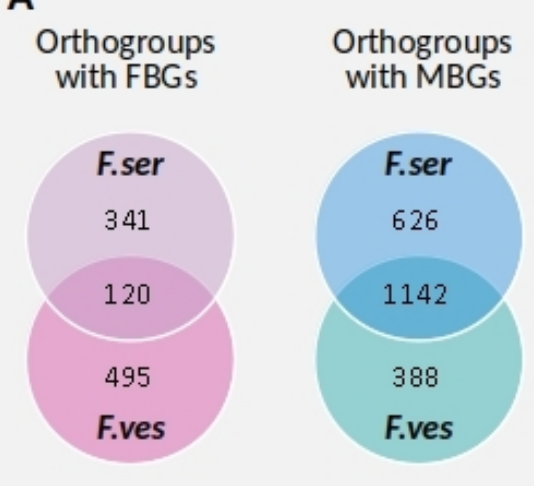

B

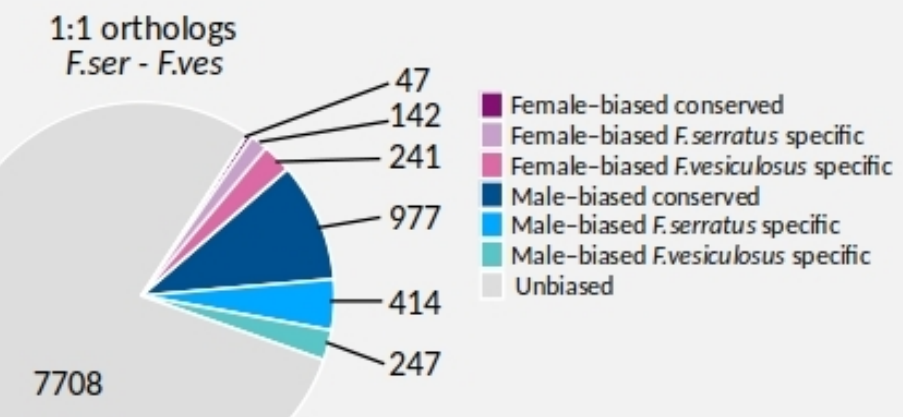

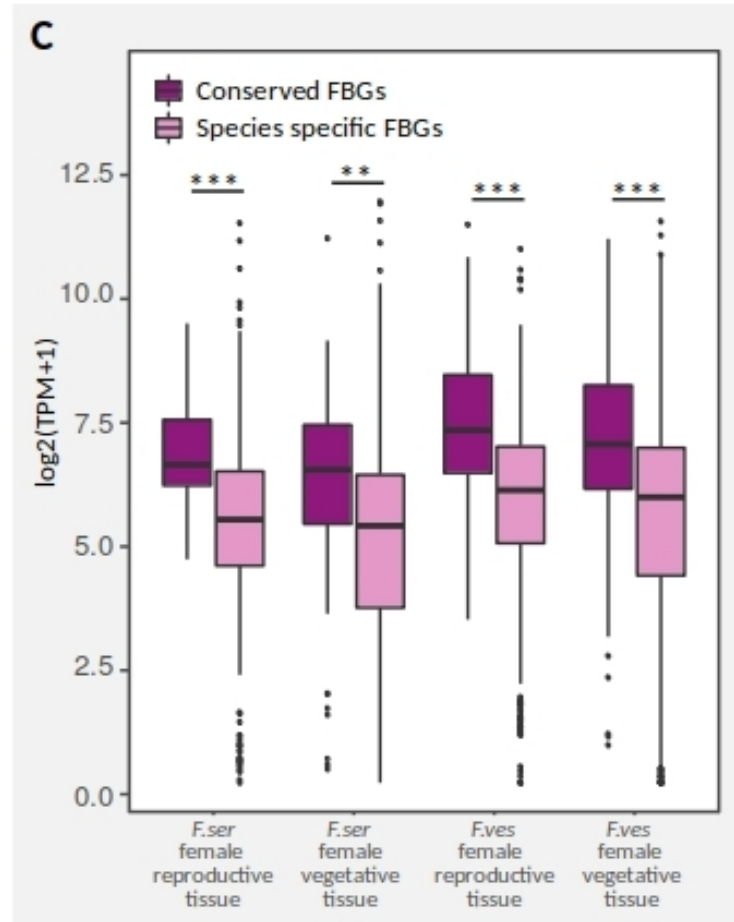

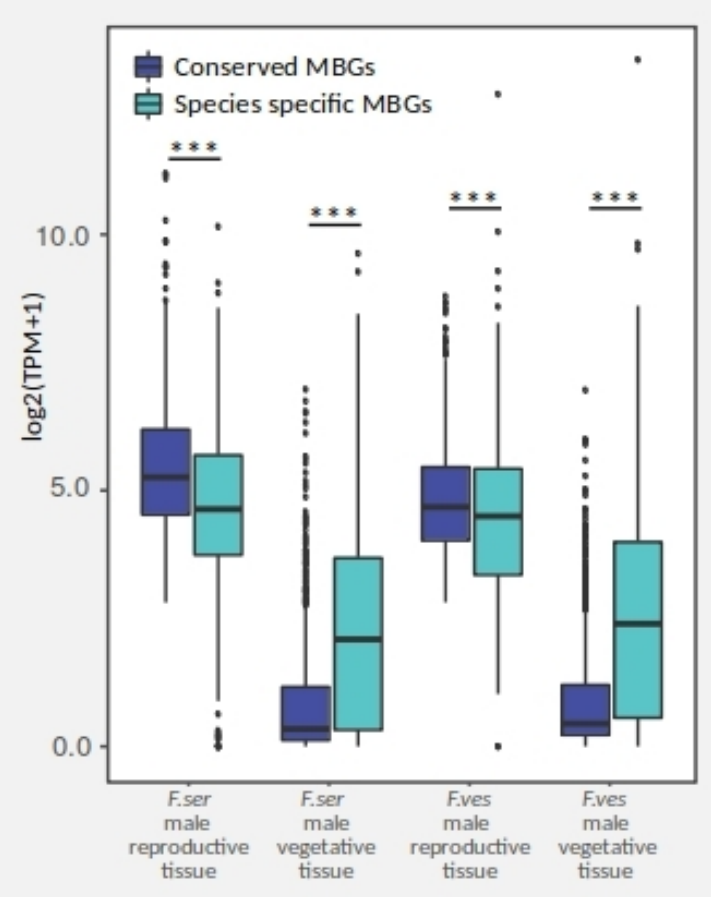

Figure 4. Conservation of sex-biased gene expression across $F$. serratus and $F$. vesiculosus species. A) Numbers of orthogroups with female (pink, FBS) and male (blue, MBS) sex-biased genes shared between dioecious species. Orthogroups with multi-copy genes of a species were included if at least one of the paralogs exhibits sex-biased expression. B) Conservation of sex-biased expression among single copy, one-to-one orthologs between F. serratus and F. vesiculosus. C) Mean expression levels (log2(TPM+1)) of conserved and speciesspecific SBGs with single copy orthologs in F. serratus and F. vesiculosus across different tissue types. Wilcoxon test, ${ }^{* *} \mathrm{p}<0.01,{ }^{* * *} \mathrm{p}<0.001$.

F.ser - Fucus serratus, F.ves - Fucus vesiculosus

The tissue specificity of male-biased genes was further highlighted in the hierarchical clustering of the one-to-one orthologs based on expression levels within and among the F. serratus and F. vesiculosus species (Fig.5). For the sex-biased genes (at least one or both orthologs are SBGs), the male reproductive samples formed a separate cluster from all the other samples (Fig.5A), which grouped primarily by phylogenetic relatedness, with female reproductive tissue appearing more similar to that of male and female vegetative tissue (Fig.5A). For unbiased genes (neither of the orthologs showed sex-bias) the samples clustered by phylogeny and tissue types (Fig.5B). 
A

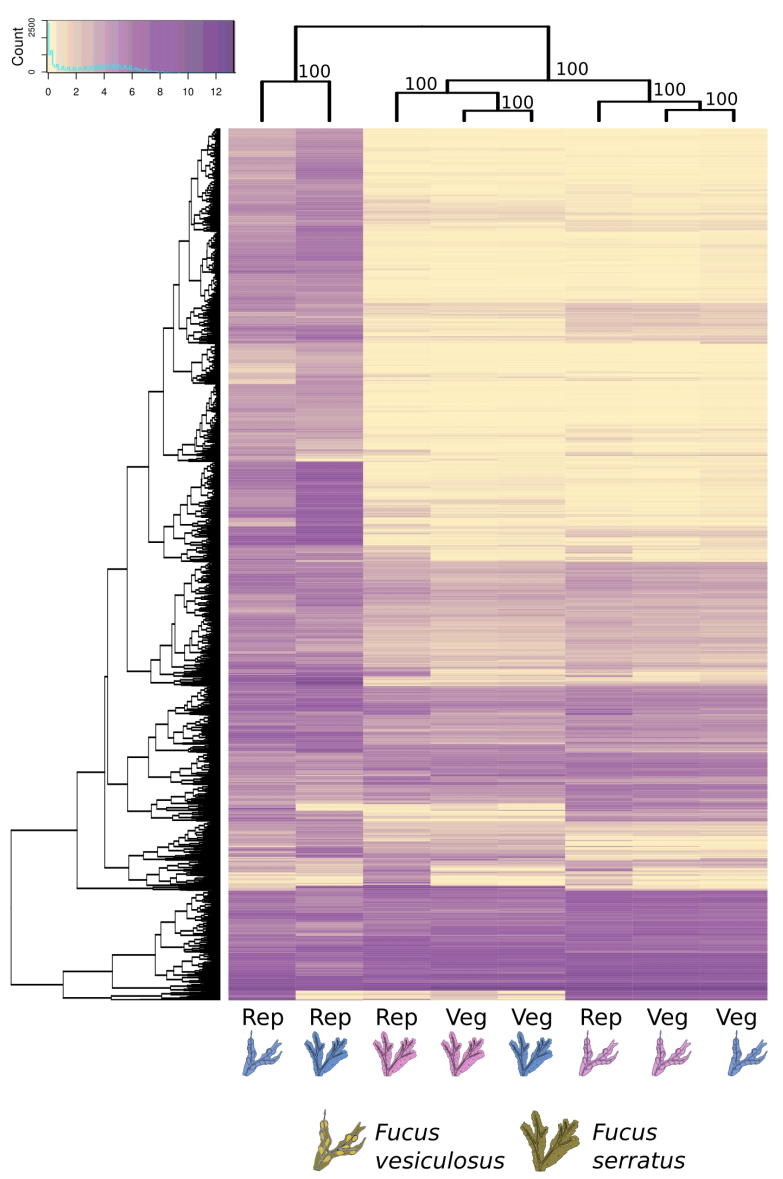

B

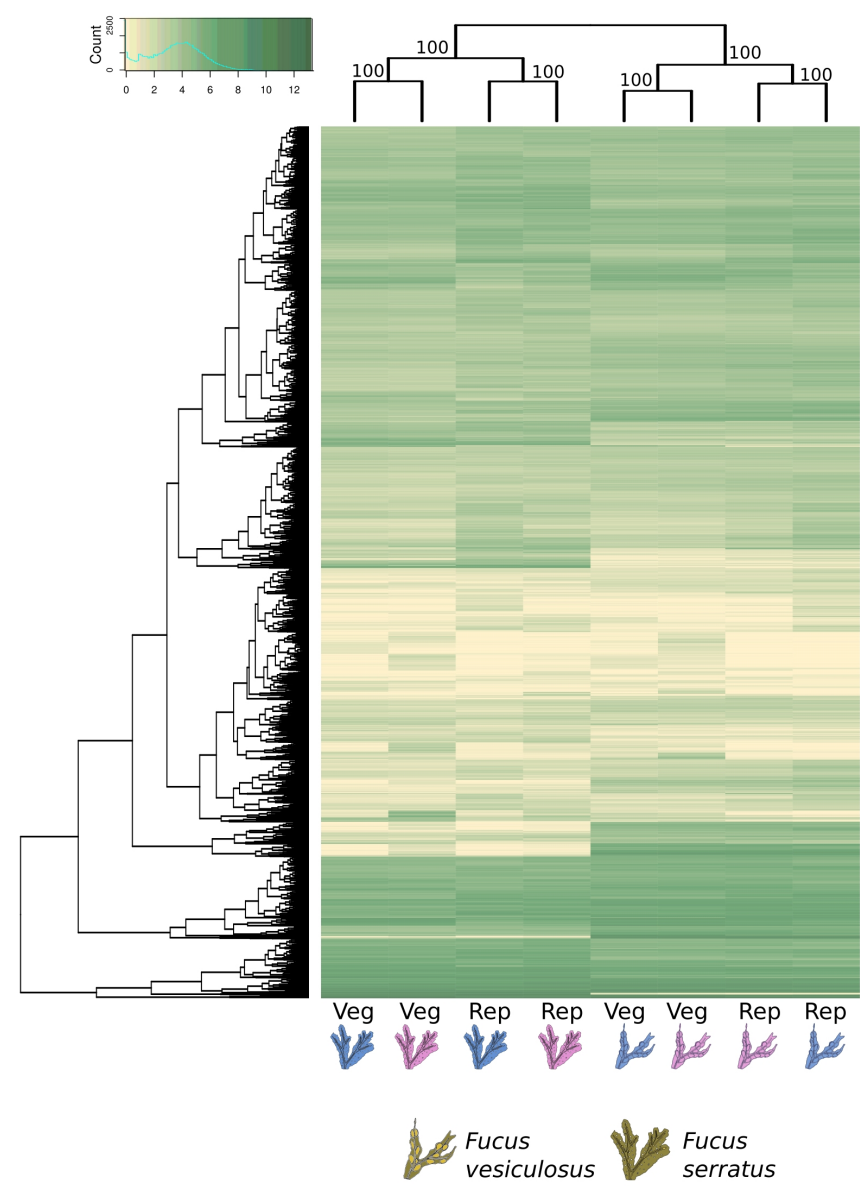

Figure 5. Heatmaps and hierarchical clustering of gene expression levels $(\log 2(T P M+1))$ for all single copy orthologs among F. serratus and F. vesiculosus. The dendogram was generated using hierarchical clustering with 1000 bootstraps (pvclust package, R). A) Sex-biased genes (at least one sex-biased gene in one of the studied species); B) unbiased genes (none of the genes was sex-biased).

Rep - Reproductive tissue, Veg - Vegetative tissue, Pink -female, Blue - male

\section{Evolution of sex-biased genes}

To investigate the role of selection on coding sequence evolution, we calculated pairwise divergence of the one-to-one orthologs within lineages (Lineage1: F. serratus - F.distichus (8,208 orthologs); Lineage2: F. vesiculosus - F.spiralis (7,363 orthologs)) using the CODEML package in PAML4 (Yang 2007).

In both dioecious species, female-biased genes showed similar rates of non-synonymous to synonymous substitutions ( $d N / d S$ ) to that of unbiased genes (Fig.6A, Wilcoxon test, $p>0.25$ ). In contrast, the average $\mathrm{dN} / \mathrm{dS}$ was significantly higher for male-biased than unbiased genes (Fig.6A, Wilcoxon test, $\mathrm{p}<8 \mathrm{e}-05)$ and did not depend on the magnitude $(\mathrm{FC})$ or conservation (universal vs species-specific) of the sex-biased expression patterns (TableS6, Wilcoxon test, $p>0.11$ ). In addition, in $F$. vesiculosus we found a significant difference in $\mathrm{dN} / \mathrm{dS}$ ratios between male SBGs and female SBGs (Fig.6A, Wilcoxon test $\mathrm{p}=0.0026$ ). Although $\mathrm{F}$. serratus showed a similar trend, the difference 
bioRxiv preprint doi: https://doi.org/10.1101/2021.08.12.455804; this version posted August 15, 2021. The copyright holder for this preprint (which was not certified by peer review) is the author/funder, who has granted bioRxiv a license to display the preprint in perpetuity. It is made available under aCC-BY-NC-ND 4.0 International license.

was not significant in (Fig.6A, Wilcoxon test $\mathrm{p}=0.074$ ).

To assess whether increased protein divergence rates were due to increased positive selection or relaxed purifying selection, we performed a maximum likelihood analysis using CODEML in PAML4 (Yang 2007). We used sequences from the four Fucus species (F. vesiculosus, F. serratus, F. distichus and F. spiralis) and two other brown alga (Ectocarpus sp. (Cock et al. 2010) and Saccharina japonica (Ye et al. 2015)) to find 561 conserved, single copy orthologs that generated high quality alignments. Among those, 57 orthologs exhibited male-biased expression and 13 exhibited female-biased expression in at least one of the dioecious Fucus species (Table S8). Each alignment was tested for direction and magnitude of selection on amino acid changes using the paired nested site models (M1a, M2a; M7, M8) implemented in PAML4 (CODEML) (Yang 2007). Likelihood ratio test calculated for either one or both pairs of models (M1a-M2a, M7-M8) detected evidence for adaptive evolution in 16 male-biased genes, 2 female-biased genes and 189 unbiased genes (Table S8). These results are consistent with the idea that sex-biased genes are subject to positive selection, although we found no significant enrichment of genes under positive selection among the sex-biased genes compared to unbiased genes (Chi square test, $p>0.05$ ).
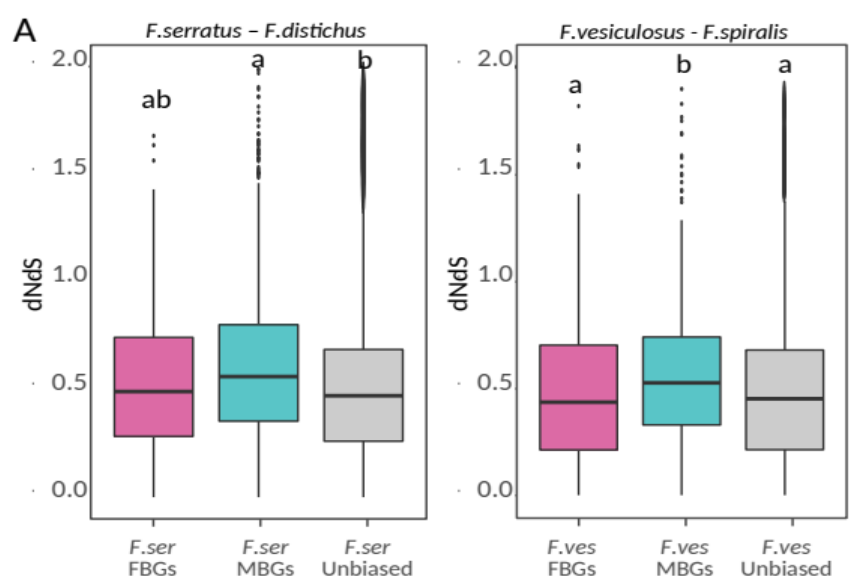

Figure 6. Evolution of sex-biased genes. A) Evolutionary rates measured as $\mathrm{dN} / \mathrm{dS}$ between species pairs (F. serratus/F.distichus and F. vesiculosus/F.spiralis) for unbiased, female-biased, and male-biased genes in the two dioecious Fucus species. B) Expression divergence measured as Euclidean distances between single copy orthologous genes of $F$. serratus and F. vesiculosus. Different letters above the plots indicate significant differences (pairwise Wilcoxon test; $p<4.3 e-10$ ). FBGs female-biased genes, MBGs - male-biased genes.
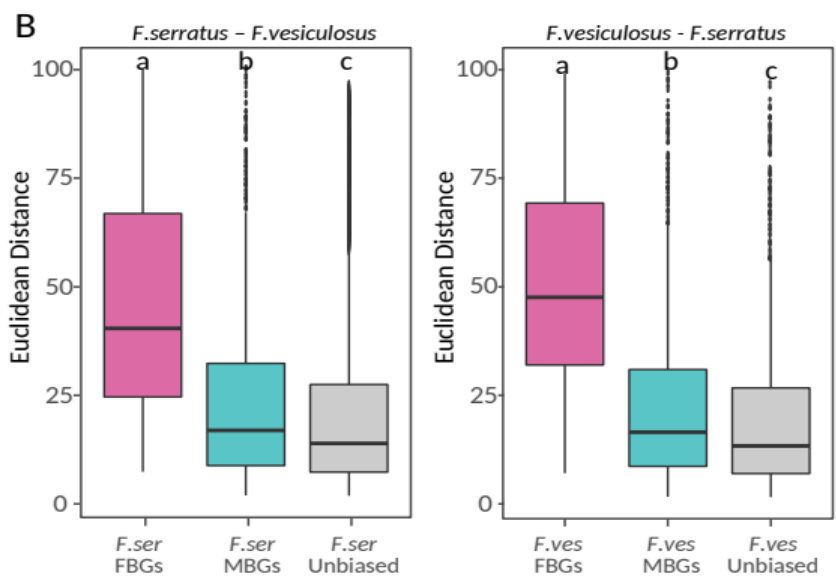

Finally, we compared the $\mathrm{dN} / \mathrm{dS}$ analysis with gene expression divergence measured as Euclidean distances for the one-to-one orthologous pairs between F. serratus and F. vesiculosus. Female-biased 
genes showed the highest divergence in expression patterns compared to male-biased or unbiased genes (Fig.6B, Wilcoxon test $\mathrm{p}<2 \mathrm{e}-16$ ). These results are in line with the higher turnover of FBGs (a given gene has a female bias in one species but it is unbiased in the other species). By comparison, male-biased genes presented more conserved expression, with the universal MBGs having overall the most stable expression patterns among all SBGs (FigS1, FigS2 Wilcoxon test $\mathrm{p}<0.003$ ).

\section{Functional analysis}

We tested for enrichment of particular molecular functions, biological processes, cellular components, or regulatory pathways in the of sex-biased genes of the two Fucus species. The Gene Ontologies (GO) associated with female-biased genes in F. serratus and $F$. vesiculosus were enriched in biological processes related to cell wall synthesis, translation, transmembrane transport, receptor signaling, photosynthesis, cell homeostasis and establishment of cell polarity (Fisher exact test, $p<0.05$, TableS7). Interestingly, analysis of male-biased genes of both species identified GO terms related to spermatogenesis and sperm competition in addition to microtubule and flagellar movement categories, as well as and photo- chemotaxis (Fisher exact test, $p<0.05$, TableS7). Furthermore, two consistently male-biased flagellar associated proteins were found to evolve under positive selection (Table S8). These result are coherent with the reproductive functions of males and females, with MBGs being predominantly involved in male germ cell differentiation, sperm motility and response to pheromones produced by the egg, whereas FBGs being related to the development of a future embryo. 
bioRxiv preprint doi: https://doi.org/10.1101/2021.08.12.455804; this version posted August 15, 2021. The copyright holder for this preprint (which was not certified by peer review) is the author/funder, who has granted bioRxiv a license to display the preprint in perpetuity. It is made available under aCC-BY-NC-ND 4.0 International license.

\section{DISCUSSION}

Brown algae are interesting models to study the evolution of sexual systems, as their extraordinary divergence in sex determination mechanisms and sexual dimorphism (ranging from isogamy to oogamy) sets them apart from other eukaryotic groups (Silberfeld et al. 2010; Coelho et al. 2019). In this work, we asked whether the recent emergence of separate sexes, and the transition to a diploid life history in Fucus serratus and Fucus vesiculosus involved concordant changes in gene expression between males and females. We investigated the proportion of the transcriptome that evolved sexbiased expression in this relatively young $X X / X Y$ system with modest sexual dimorphism. We also examined if the evolutionary patterns of sex-biased genes in Fucus are convergent with the ones found in well-established XY or ZW systems.

\section{Sex-biased expression in dioecious Fucus species}

While very few genes were differentially expressed between male and female vegetative tissue, thousands of genes (ca. 8-9\% of F. serratus and F. vesiculosus transcriptomes, respectively) were differentially expressed in the reproductive tissues. A similar fraction of the genome displayed tissuebiased expression between receptacles and the rest of the body within each sex, allocating the majority of tissue- and sex-biased expression to the reproductive organs. These findings comply with the general trend found in animals and plants where reproductive tissues show the highest expression divergence between sexes (animals: Yang et al. 2006; Yang 2007; Pointer et al. 2013; Harrison et al. 2015; Allen et al. 2018; plants: Song et al. 2017; Darolti et al. 2018). This could be expected in Fucus, as sexes are morphologically identical except for their receptacles. The overall moderate levels of SBG expression in Fucus (8-9\%, compared to $>50 \%$ in in Drosophila (Ranz et al. 2003) and wild turkey (Pointer et al. 2013)) may be be explained by the lowlevels of sexual dimorphism, external fertilization mode and, accordingly, more narrow range of sexual selection in both F. serratus and F. vesiculosus (Luthringer et al. 2014). In birds, the proportion of SBGs corresponded with the strength of selection and the extent of phenotypic dimorphism between males and females (Harrison et al. 2015). Similarly, in a male feminized mutant strain of the brown alga Macrocystis, sex-specific phenotypes (male, female or feminized male variant) showed sexspecific transcriptomic patterns (Müller et al. 2021). It is worth noting that the proportion of SBGs in the oogamous Fucus much exceeded that of the near-isogamous Ectocarpus (Lipinska et al. 2015). Ectocarpus is a filamentous brown alga with low levels of sexual dimorphism between the male and female gametophytes, has a haploid-diploid life cycle and produces morphologically similar, small, flagellated male and female gametes (Luthringer et al. 2014; Lipinska et al. 2015). In Ectocarpus, obscure phenotypic sexual dimorphism corresponded to less than $4 \%$ (658) of genes being sex-biased 
bioRxiv preprint doi: https://doi.org/10.1101/2021.08.12.455804; this version posted August 15, 2021. The copyright holder for this preprint (which was not certified by peer review) is the author/funder, who has granted bioRxiv a license to display the preprint in perpetuity. It is made available under aCC-BY-NC-ND 4.0 International license.

during the reproductive stage compared to $8 \%(2,993)$ in $F$. serratus and $9 \%(2,772)$ in $F$. vesiculosus in our study. Furthermore, in oogamous kelp Macrocystis, where male and female gametophytes have visibly distinct morphologies (Müller et al. 1979), sex-biased gene expression analysis found $24 \%(5,442)$ of genes with male/female bias (Müller et al. 2021). In summary, our results suggest that the evolution of anisogamy alone, without the other morphologically dimorphic characters, has triggered a significant increase in sex-biased gene expression.

\section{Masculinization of the Fucus transcriptome}

In both systems, Ectocarpus with UV, and Fucus with XX/XY sex chromosomes, we identified an excess of male-biased over female-biased genes. However, in Fucus species male overexpression was much more pronounced, exceeding more than three times the number of FBGs (400 MBGs vs 258 FBGs in Ectocarpus; 2,315 MBGs vs 678 FBGs in F. serratus; 2,025 MBGs vs 747 FBGs in F. vesiculosus). Globally, male-biased genes featured extreme expression bias (FC>20) with more than half of the male-biased genes being male specific, expressed explicitly in male receptacles, and at significantly lower levels than unbiased genes in the vegetative tissue. This masculinization of the transcription profile may result from adaptive changes in males, and, as predicted for anisogamy, implies that males experience stronger selection than females (Darwin 1871; Bateman 1948; Parker 1979; Schärer et al. 2012; Andersson 2019). Masculinization of the transcriptome has been found in many other species and could be due to the relative expression of male sexual traits, female choice and male-male competition (Connallon and Knowles 2005; Pointer et al. 2013; Harkess et al. 2015; Zemp et al. 2016). Although female choice in the 'classical' understanding does not exist in freespawning species like Fucus, it could still occur at the level of gametes or post-fertilization. Evidence for 'gamete-mediated mate choice' (GMMC) across many different mating systems and the its evolutionary significance of non-random interactions among gametes to the the evolutionary origins of more definite forms of mate choice was recently reviewed by (Kekäläinen and Evans 2018). On the other hand, sperm competition would be facilitated in the water column, where ejaculates from different males mix and compete for fertilization of the egg. To test the hypothesis that the sexualization of the transcriptomes of the Fucus species was associated with increased sexual selection in males, we would need to compare our data with transcriptomic data from closely related hermaphrodite species. For example, gene expression data from members of the two Fucales families that remained monoecious (Sargassaceae and Notheiaceae) could serve as a baseline to asses the direction of changes in expression that led to sex-bias in F. serratus and F. vesiculosus (Heesch et al. 2021).

In contrast to MBGs, female-biased genes seemed to be uniformly and highly expressed throughout the female and male body. This overall homogeneous expression pattern of FBGs became apparent 
bioRxiv preprint doi: https://doi.org/10.1101/2021.08.12.455804; this version posted August 15, 2021. The copyright holder for this preprint (which was not certified by peer review) is the author/funder, who has granted bioRxiv a license to display the preprint in perpetuity. It is made available under aCC-BY-NC-ND 4.0 International license.

when vegetative and reproductive tissue within each sex were compared (so called tissue-biased expression, as opposed to sex-biased expression where the same tissue types are compared between the two sexes). The majority of FBGs did not show tissue-biased expression in females (79\% in $\mathrm{F}$. serratus and $91 \%$ in F. vesiculosus), and only 20 and 22 genes showed sex-bias in vegetative tissue in F. serratus and F. vesiculosus, respectively. To summarize, sexual conflict over gene expression in Fucus appear to be resolved by the down-regulation of expression of pleiotropic female genes in male receptacles and by restricting the expression of MBGs to the male reproductive tissue, resulting in masculinized transcriptomes as previously reported for the giant kelp Macrocystis (Müller et al. 2021).

\section{High conservation of male-biased expression}

Male-biased genes are highly conserved between the two Fucus species, which contrasts with the overall trends found in other species. MBGs in Fucus presented not only the conservation of bias, but also of expression levels (measured as Euclidean distance) which resulted in clustering of the male reproductive samples by sex rather than by species. The changes in male-biased gene regulation may have risen in the common ancestor of F. serratus and F. vesiculosus and shared ancestry could be, therefore, responsible for the observed correlation. This would further support a hypothesis that dioecy was the ancestral state in the Fucus genus and co-sexuality in F.distichus and F.spiralis is a derived state. However, previous reports have shown that the targets of sex-biased expression can change over a short evolutionary time and that a small fraction of genes show parallel changes in recently diverged species (Ranz et al. 2003; Harrison et al. 2015; Huylmans et al. 2017). Similarly, studies on plants failed to find genes that were consistently sex-biased but, instead, concluded that the sex-biased gene expression was unique in each species (Scharmann et al. 2021).

Given the relatively young evolutionary age of our system, phenotypic differences accumulated between and within species may be insufficient to drive the turnover of sex-biased genes. However, this is unlikely since the number of single copy orthologs with male-biased expression (in both species) exceeded four times the number of unbiased genes with one-to-one orthologs, suggesting that the MBGs are selectively conserved. Functional analysis of male-biased genes in both species further support this assumption, as MBGs were consistently enriched in ontologies that would be important to male fertility, related to sperm production, motility and function. In contrast to MBGs, FBGs experienced higher turnover rates and had species specific expression patterns indicated by significantly increased Euclidean distance values, compared to both unbiased and male-biased genes. Taken together, if intralocus conflict is the main driver of sex-biased expression, our results suggest that the targets of this conflict are fixed in males, but not in females of both, Fucus serratus and Fucus vesiculosus. 


\section{Evolution of sex-biased genes}

Sex-biased genes, tend to evolve faster than unbiased genes, and this is particularly true for malebiased genes (Meiklejohn et al. 2003; Harrison et al. 2015; Lipinska et al. 2015; Darolti et al. 2018). Although male-biased genes displayed conserved expression between Fucus species, they presented higher rates of protein evolution compared to unbiased genes, in both Fucus serratus and Fucus vesiculosus. Both, positive selection in males or relaxed selection in females may be responsible for rapid DNA sequence evolution of MBGs (Zhang et al. 2004b; Dyken and Wade 2010; Gershoni and Pietrokovski 2014; Gossmann et al. 2014; Mank 2017). Accordingly, we found 16 MBGs (30\% of analyzed male-biased genes) with signatures of positive selection. Interestingly, two of these genes were associated with the sperm flagella suggesting that positive selection of male-biased genes could result from stronger sexual selection driven by e.g. sperm competition in Fucus. The fraction of MBGs under selection was, however, not significantly different to that observed for unbiased genes, indicating that adaptive evolution contributes partially, but is not the main driver of the elevated substitution rates in MBGs.

Alternatively, other aspects of genetic architecture could be contributing to the rapid evolution of male-biased genes. For example, MBGs could be less constrained by pleiotropy, because their expression is predominantly confined to male reproductive tissue, which is often associated with patterns of faster sequence evolution (Meisel 2011; Grath and Parsch 2012; Darolti et al. 2018). In line with this, female-biased genes in Fucus are expressed in both vegetative and reproductive tissue in male and female gametophytes, and show lower rates of synonymous to non-synonymous substitutions. Further, the rate of evolution could be determined by the genomic location of MBGs, specifically the sex-chromosome linkage. Elevated rates of coding sequence evolution on the sex chromosome relative to autosomes have been reported for several species, consistent with the theoretical prediction of fast-X or fast-Z evolution (Kirkpatrick and Hall 2004; Mank et al. 2010; Belleghem et al. 2018). In Fucus, male-biased genes show high expression levels only in the male reproductive tissue, and the fast- $X$ theory predicts that genes highly expressed in the hemizygous sex should be especially prone to fast-X evolution (Meisel et al. 2012). This interesting aspect of MBGs evolution should be revisited in the future when the genome sequences of Fucus serratus and Fucus vesiculosus become available. Finally, the set of MBGs could be enriched for young genes, which are known to evolve more rapidly (Gossmann et al. 2016). However, to assess the evolutionary age of Fucus sex-biased genes, additional data from closely related species is needed.

In summary, MBGs and FBGs in Fucus seem to follow different evolutionary path and are under different selective pressure. MBGs evolve faster at the level of the protein sequence, but their expression levels remain very conserved between Fucus species. In contrast, FBGs do not show 

made available under aCC-BY-NC-ND 4.0 International license.

accelerated rates of coding sequences evolution, but rather higher diversification of their expression levels. Because the changes in coding and regulatory sequences are often decoupled, it has been suggested that they play different evolutionary roles in the evolution of morphological and physiological characters (Connallon and Knowles 2005; Wray 2007; Tirosh and Barkai 2008; Liao et al. 2009, Loehilin 2019, Martin 2013). Changes in regulatory sequences enhancing physiological diversity and changes in protein sequences affecting morphology. Both type of changes (morphological or physiological) could be under selection due to reinforcement, since members of both linages (F. serratus-F. distichus and F. vesiculosus-F.spiralis) show signatures of ongoing or past hybridization, and hybrids of the dioecious F. serratus- F. vesiculosus are extremely rare (Coyer et al. 2002; Wallace et al. 2004; Billard et al. 2005; Coyer et al. 2007; Hoarau et al. 2015). Furthermore, studies of geographical hybrid zones of F. serratus and F.distchus (Lineage 1) show signatures of reinforcement of pre-zygotic isolation namely decreasing rates of hybridization and interspecific fertilization success with increasing duration of sympatry (Hoarau et al. 2015). Further studies are needed to characterize the genetic basis of reproductive isolation in Fucus as well as the connection between prezygotic barriers to fertilization and within-species sexual selection. 


\section{METHODS}

\section{Sampling}

Four species of Fucus were collected from the intertidal shoreline at Mjelle, Norway $\left(67^{\circ} 24^{\prime} 47.3^{\prime \prime} \mathrm{N}\right.$ 14³7'49.3"E) in May 2017 (TableS1); two dioecious-F. serratus and F. vesiculosus-and two monoecious $F$. distichus and F. spiralis. All four species were reproductively mature. To ensure availability of three replicates from each tissue type, (vegetative and reproductive tissues from males and female $s$ for dioecious species), 10 individuals were collected from each monoecious species (F. spiralis and F. distichus) and 20 from each dioecious species (F. serratus and F. vesiculosus). Samples were transported to the laboratory in a cooler box within an hour of collection, in autoclaved seawater at $4^{\circ} \mathrm{C}$. The dioecious species were sexed by confirming the presence of antheridia (male) or oogonia (female) in the receptacles with a microscope. Receptacles and small segments of vegetative tissue were dissected from both monoecious and dioecious individuals and wrapped separately in aluminium foil to prevent contamination and for optimum flash freezing conditions in liquid nitrogen. All samples were stored at $-80^{\circ} \mathrm{C}$, then freeze-dried using a VirTis Bench Top K Freeze dryer befor subsequent RNA extraction .

\section{RNA extraction, library preparation and sequencing}

Total RNA was extracted from $5 \mathrm{mg}$ of freeze-dried sample from every biological replicate as described in (Pearson et al. 2006). Samples were purified with the ZR-96 RNA Clean \& Concentrator kit (Zymo Research, Irvine, USA) and potential PCR inhibitors were removed with the OneStep-96TM PCR Inhibitor Removal Kit (Zymo Research). RNA concentrations were quantified with the Qubit RNA Assay kit (Life Technologies, Paisley, UK) using a Qubit 2.0 Fluorometer and tested for both quantity and integrity using RNA screen tape (Agilent Technologies, Waldbronn, Germany) on the Agilent 2200 Tapestation.

Sequencing libraries were prepared from $1 \mu \mathrm{g}$ RNA using the NEBNext Ultra II Directional RNA Library Prep Kit for Illumina (New England Biolabs). Incubation time for fragmentation of total RNA was 6 mins and no size selection was performed. The libraries were sequenced twice on the Illumina NextSeq 500 (150-bp pair-end reads), using the NextSeq 500/550 High Output Kit v2.5 (300 Cycles).

\section{RNAseq analysis and de novo reference transcriptome assembly}

Sequencing data were demultiplexed using the Bcl2Fastq Conversion Software (v. 2.20, Illumina). Raw sequences were adapter- and quality-trimmed with Trimmomatic (v. 0.33) (Bolger et al. 2014), followed by a standard quality check using FastQC (v. 0.11.4) (Andrews 2010), to control for aberrant read base content, length distribution, duplication and read over-representation. Prior to de novo transcriptome assembly, the reads were normalized to reduce redundancy of overrepresented sequences, using Trinity's in silico read normalization utility (v. 2.8.5). A reference transcriptome per 
bioRxiv preprint doi: $\mathrm{https}$ ://doi. org/10.1101/2021.08.12.455804; this version posted August 15, 2021. The copyright holder for this preprint (which was not certified by peer review) is the author/funder, who has granted bioRxiv a license to display the preprint in perpetuity. It is made available under aCC-BY-NC-ND 4.0 International license.

species was generated from the normalized reads (all replicates and conditions combined), using Trinity's de novo assembly (Grabherr et al. 2011; Haas et al. 2013). Isoforms were collapsed into single gene sequences using a Trinity_gene_splice_modeler.py script from the Trinity toolkit and used for downstream analyses.

The predicted genes generated from the de novo assembly were then blasted against a custom bacterial/reference genomes database to identify and eliminate bacterial contamination. The longest open reading frames (ORFs) were constructed using Transdecoder (v. 5.5.0) (Haas et al. 2013), to reduce the redundant non-coding regions in the sequences. The ORFs were then blasted against an in-house heterokont database and a standard UniProt and Pfam database to keep the most likely ORFs. Transdecoder.Predict was used to predict the best coding regions with homology search results (Pfam and heterokont results) and genes without a coding region of at least 100bp were removed from the dataset. Trinity's CD-HIT-EST (v. 4.6) (Li et al. 2001) clustered genes with predicted ORFs to further reduce the number of redundant sequences, thus generating the final reference gene sets for each species. Transcript abundances were then quantified using Kallisto (Bray et al. 2016) with 1000 bootstraps and represented as TPM (transcript per million). Genes with $\log _{2}(T P M+1)<1$ were considered not expressed.

Orthofinder (v. 2.3.3 ) (Emms and Kelly 2019) was used to find orthologous genes between all four Fucus species (TableS1). Orthofinder assigns homologous proteins (orthologs and/or paralogs) to orthogroups (OGs), so that one or more of the studied species are represented in each OG by a single-copy or multi-copy genes of common ancestry. Orthogroups with multi-copy genes allow to detect gene duplication events and provide information about conservation of genes of interest across species. They are not, however, suitable for direct gene comparisons (sequence evolution; expression levels) since it is not possible to discriminate between paralogous genes. Therefore, we used OGs with single and/or mulicopy-genes to study global patterns of conservation of sex-biased expression in the dioecious species pair; and OGs with strictly single copy genes for the evolutionary and comparative expression analyses. Orphan genes (i. e., taxonomically restricted genes) were defined as genes present in the reference transcriptome of only one species and having no BLASTp match (10-04e value cutoff) in the other Fucus species.

\section{Differential gene expression analysis}

Differential gene expression within species (between sexes and tissue types) was tested with the DESeq2 package (v. 3.9 bioconductor) (Love et al. 2014). Genes with fold change $F C>=2$ and $p_{\text {adj }}$ $<0.05$ were considered significantly differentially expressed (Benjamini-Hochberg method) and were labeled with corresponding tissue types (male, female, reproductive and vegetative). Those genes that did not show significant differential expression were labeled unbiased. 


\section{Evolutionary analysis}

Amino acid sequences of the single copy orthologous genes between F. serratus-F.distichus and F. vesiculosus-F.spiralis were aligned using MAFFT (v. 7.450) (Katoh et al. 2002) and translated back to nucleotide alignments using Pal2Nal (v. 14) (Suyama et al. 2006). The alignments were trimmed using Gblocks with a minimum block length of 20 . In order to remove poorly aligned sequences that could bias the evolutionary analysis, we realigned all the fasta files with EMBOSS Water (version 6.6.0) (Madeira et al. 2019) and removed alignments with $<80 \%$ similarity. The remaining high quality, gapless alignments exceeding $100 \mathrm{bp}$ in length were retained for pairwise $\mathrm{dN} / \mathrm{dS}(\omega)$ analysis using phylogenetic analysis by maximum likelihood (PAML4, CodeML, F3x4 model of codon frequencies, runmode $=-2$ ) (Yang 2007).

The positive selection analysis was carried out using CodeML (PAML4, F3x4 model of codon frequencies) using single copy orthologs of the four Fucus species (F. serratus, F. vesiculosus, F.distichus and F.spiralis) and two other brown algal species (Ectocarpus sp. (Cock et al. 2010) and Sacchraina japonica (Ye et al. 2015)). Protein alignment and curation was performed as described above. Gapless alignments longer than $100 \mathrm{bp}$ containing sequences from all six species species were retained for subsequent analysis. CODEML paired nested site models (M1a, M2a; M7, M8) (Yang 2007) of sequence evolution were used, and the outputs compared using the likelihood ratio test.

Euclidean distances were estimated for all single copy orthologs between $F$. serratus and $F$. vesiculosus following the approach of (Pereira et al. 2009). The following formula was used:

$$
\operatorname{EucD}=\sqrt{\sum_{j=1}^{k}\left(x_{1 j}-x_{2 j}\right)^{2}}
$$

where $x_{i j}$ is the expression level of the gene under consideration (TPM) in species $i$ (i.e., species 1 or species 2) during stage $j$ and $k$ is the total number of stages (i.e., four, male and female individuals, reproductive and vegetative tissues). All statistical analysis was performed using RStudio ( $\mathrm{R}$ version 3.6.3).

\section{Gene Ontology analysis}

EggNOG v5.0 (Huerta-Cepas et al. 2019) was used to perform functional annotation of F. serratus and F. vesiculosus genes. We used topGO package in R (Alexa and Rahnenfuhrer 2020) to detect enrichment of specific GO terms in sex-biased genes (Fisher's exact test with a p-value cutoff of 0.05).

\section{Acknowledgments}

This work was supported by NORD University, Norway (PhD grant to WH). 


\section{Data Availability}

Raw sequence data have been submitted to NCBI SRA under BioProject PRJNA731608. The Transcriptome Shotgun Assembly projects have been deposited at DDBJ/EMBL/GenBank under the accessions GJHR00000000, GJHF00000000, GJHG00000000 and GJHE00000000. The version described in this paper is the first version, GJHR01000000, GJHF00000000, GJHG00000000 and GJHEO0000000.

\section{Supplementary data}

Table S1. Sequencing and assembly summary.

Table S2. Number of sex-biased and tissue-biased genes in F. serratus and F. vesiculosus; DESeq2 (FC>=2, pdj<0.05).

Table S3. Expression levels $(\log 2(\mathrm{TPM}+1)$ and fold change $(\log \mathrm{FC})$ of sex-biased and tissue-biased genes in $F$. serratus and $F$. vesiculosus.

Table S4. Gene orthology statistics.

Table S5. Orphan genes among the sex-biased genes in F. serratus and F. vesiculosus.

Table S6. Evolutionary rates measured as $\mathrm{dN} / \mathrm{dS}$ between species pairs ( $F$. serratus/F.distichus and F. vesiculosus/F.spiralis) for unbiased, female-biased, and male-biased genes.

Table S7. Gene Ontology enrichment of the sex-biased genes in F. serratus and F. vesiculosus, Fisher exact test, $\mathrm{p}<0.01$.

Table S8. Positive selection analysis; PAML codeml with the F3X4 substitution model.

FigS1. Heatmap of gene expression levels $(\log 2(T P M+1))$ of sex-biased genes among single copy orthologs in F. serratus and F. vesiculosus (at least one of the orthologs is sex-biased in one of the studied species). Orthologs are grouped by the conservation of sex-biased expression indicated by the colour panel on the left. Rep - Reproductive tissue, Veg - Vegetative tissue.

FigS2. Expression divergence measured as Euclidean distances between single copy orthologous genes of F. serratus and F. vesiculosus. Sex-biased genes are divided into groups based on their conserved (orthologs show sex bias in both species) or species-specific (only one of the orthologs is sex biased in either F. serratus or F. vesiculosus) expression. Different letters above the plots indicate significant differences (pairwise Wilcoxon test; $p<0.05$ ). 
bioRxiv preprint doi: https://doi.org/10.1101/2021.08.12.455804; this version posted August 15, 2021. The copyright holder for this preprint (which was not certified by peer review) is the author/funder, who has granted bioRxiv a license to display the preprint in perpetuity. It is made available under aCC-BY-NC-ND 4.0 International license. 


\section{REFERENCES}

Alexa A, Rahnenfuhrer J. 2020. topGO: Enrichment Analysis for Gene Ontology. R package version 2.42.0.

Allen SL, Bonduriansky R, Chenoweth SF. 2018. Genetic constraints on microevolutionary divergence of sex-biased gene expression. Philosophical Transactions of the Royal Society B: Biological Sciences 373:20170427.

Andersson M. 2019. Sexual Selection. Princeton University Press

Andrews S. 2010. FastQC: a quality control tool for high throughput sequence data. Available online at: http://www.bioinformatics.babraham.ac.uk/projects/fastqc. Online.

Arrontes J. 1993. Nature of the distributional boundary of Fucus serratus on the north shore of Spain. Marine Ecology Progress Series 93:183-193.

Assis R, Zhou Q, Bachtrog D. 2012. Sex-biased transcriptome evolution in Drosophila. Genome Biol Evol 4:1189-1200.

Ayroles JF, Carbone MA, Stone EA, Jordan KW, Lyman RF, Magwire MM, Rollmann SM, Duncan LH, Lawrence F, Anholt RRH, et al. 2009. Systems genetics of complex traits in Drosophila melanogaster. Nature Genetics 41:299-307.

Baldauf SL. 2003. The deep roots of eukaryotes. Science 300:1703-1706.

Bateman AJ. 1948. Intra-sexual selection in Drosophila. Heredity (Edinb) 2:349-368.

Belleghem SMV, Baquero M, Papa R, Salazar C, McMillan WO, Counterman BA, Jiggins CD, Martin SH. 2018. Patterns of $Z$ chromosome divergence among Heliconius species highlight the importance of historical demography. Molecular Ecology 27:3852-3872.

Billard E, Daguin C, Pearson G, Serrão E, Engel C, Valero M. 2005. Genetic Isolation Between Three Closely Related Taxa: Fucus Vesiculosus, F. Spiralis, and F. Ceranoides (phaophyceae)1. Journal of Phycology 41:900-905.

Blekhman R, Marioni JC, Zumbo P, Stephens M, Gilad Y. 2010. Sex-specific and lineagespecific alternative splicing in primates. Genome Res 20:180-189.

Bolger AM, Lohse M, Usadel B. 2014. Trimmomatic: a flexible trimmer for Illumina sequence data. Bioinformatics 30:2114-2120.

Brawley SH. 1992. Fertilization in natural populations of the dioecious brown alga Fucus ceranoides and the importance of the polyspermy block. Marine Biology 113:145157.

Bray NL, Pimentel H, Melsted P, Pachter L. 2016. Near-optimal probabilistic RNA-seq quantification. Nat Biotechnol 34:525-527.

Cánovas FG, Mota CF, Serrão EA, Pearson GA. 2011. Driving south: a multi-gene phylogeny of the brown algal family Fucaceae reveals relationships and recent drivers of a marine radiation. BMC Evolutionary Biology 11:371. 
Cock JM, Sterck L, Rouzé P, Scornet D, Allen AE, Amoutzias G, Anthouard V, Artiguenave F, Aury J-M, Badger JH, et al. 2010. The Ectocarpus genome and the independent evolution of multicellularity in brown algae. Nature 465:617-621.

Coelho SM, Gueno J, Lipinska AP, Cock JM, Umen JG. 2018. UV Chromosomes and Haploid Sexual Systems. Trends Plant Sci. 23:794-807.

Coelho SM, Mignerot L, Cock JM. 2019. Origin and evolution of sex-determination systems in the brown algae. New Phytologist 222:1751-1756.

Connallon T, Knowles LL. 2005. Intergenomic conflict revealed by patterns of sex-biased gene expression. Trends in Genetics 21:495-499.

Cossard GG, Toups MA, Pannell JR. 2019. Sexual dimorphism and rapid turnover in gene expression in pre-reproductive seedlings of a dioecious herb. Ann Bot 123:11191131.

Cox RM, Calsbeek R. 2009. Sexually antagonistic selection, sexual dimorphism, and the resolution of intralocus sexual conflict. Am Nat 173:176-187.

Coyer JA, Hoarau G, Oudot-Le Secq M-P, Stam WT, Olsen JL. 2006. A mtDNA-based phylogeny of the brown algal genus Fucus (Heterokontophyta; Phaeophyta). Molecular Phylogenetics and Evolution 39:209-222.

Coyer JA, Hoarau G, Stam WT, Olsen JL. 2007. Hybridization and introgression in a mixed population of the intertidal seaweeds Fucus evanescens and F. serratus. Journal of Evolutionary Biology 20:2322-2333.

Coyer JA, Peters AF, Hoarau G, Stam WT, Olsen JL. 2002. Hybridization of the marine seaweeds, Fucus serratus and Fucus evanescens (Heterokontophyta: Phaeophyceae) in a 100-year-old zone of secondary contact. Proceedings of the Royal Society of London. Series B: Biological Sciences 269:1829-1834.

Cutter AD. 2018. X exceptionalism in Caenorhabditis speciation. Molecular Ecology 27:39253934.

Darolti I, Wright AE, Pucholt P, Berlin S, Mank JE. 2018. Slow evolution of sex-biased genes in the reproductive tissue of the dioecious plant Salix viminalis. Mol Ecol 27:694-708.

Darwin C. 1871. The descent of man and selection in relation to sex. John Murray

Dyken JDV, Wade MJ. 2010. The Genetic Signature of Conditional Expression. Genetics 184:557-570.

Ellegren H, Parsch J. 2007. The evolution of sex-biased genes and sex-biased gene expression. Nat. Rev. Genet. 8:689-698.

Emms DM, Kelly S. 2019. OrthoFinder: phylogenetic orthology inference for comparative genomics. Genome Biology 20:238.

Gershoni M, Pietrokovski S. 2014. Reduced selection and accumulation of deleterious mutations in genes exclusively expressed in men. Nat Commun 5:4438. 
Gossmann TI, Saleh D, Schmid MW, Spence MA, Schmid KJ. 2016. Transcriptomes of Plant Gametophytes Have a Higher Proportion of Rapidly Evolving and Young Genes than Sporophytes. Mol Biol Evol 33:1669-1678.

Gossmann TI, Schmid MW, Grossniklaus U, Schmid KJ. 2014. Selection-Driven Evolution of Sex-Biased Genes Is Consistent with Sexual Selection in Arabidopsis thaliana. Mol Biol Evol 31:574-583.

Grabherr MG, Haas BJ, Yassour M, Levin JZ, Thompson DA, Amit I, Adiconis X, Fan L, Raychowdhury R, Zeng $Q$, et al. 2011. Full-length transcriptome assembly from RNASeq data without a reference genome. Nat. Biotechnol. 29:644-652.

Grath S, Parsch J. 2012. Rate of Amino Acid Substitution Is Influenced by the Degree and Conservation of Male-Biased Transcription Over 50 Myr of Drosophila Evolution. Genome Biology and Evolution 4:346-359.

Grath S, Parsch J. 2016. Sex-Biased Gene Expression. Annual Review of Genetics 50:29-44.

Haas BJ, Papanicolaou A, Yassour M, Grabherr M, Blood PD, Bowden J, Couger MB, Eccles D, Li B, Lieber M, et al. 2013. De novo transcript sequence reconstruction from RNASeq: reference generation and analysis with Trinity. Nat Protoc [Internet] 8. Available from: https://www.ncbi.nlm.nih.gov/pmc/articles/PMC3875132/

Harkess A, Mercati F, Shan H-Y, Sunseri F, Falavigna A, Leebens-Mack J. 2015. Sex-biased gene expression in dioecious garden asparagus (Asparagus officinalis). New Phytologist 207:883-892.

Harrison PW, Wright AE, Zimmer F, Dean R, Montgomery SH, Pointer MA, Mank JE. 2015. Sexual selection drives evolution and rapid turnover of male gene expression. PNAS 112:4393-4398.

Hayward A, Gillooly JF. 2011. The Cost of Sex: Quantifying Energetic Investment in Gamete Production by Males and Females. PLOS ONE 6:e16557.

Hedrick AV, Temeles EJ. 1989. The evolution of sexual dimorphism in animals: Hypotheses and tests. Trends Ecol Evol 4:136-138.

Heesch S, Serrano-Serrano M, Barrera-Redondo J, Luthringer R, Peters AF, Destombe C, Cock JM, Valero M, Roze D, Salamin N, et al. 2021. Evolution of life cycles and reproductive traits: Insights from the brown algae. Journal of Evolutionary Biology 34:992-1009.

Hoarau G, Coyer JA, Giesbers MCWG, Jueterbock A, Olsen JL. 2015. Pre-zygotic isolation in the macroalgal genus Fucus from four contact zones spanning 100-10 000 years: a tale of reinforcement? Royal Society Open Science 2:140538.

Hoarau G, Coyer JA, Veldsink JH, Stam WT, Olsen JL. 2007. Glacial refugia and recolonization pathways in the brown seaweed Fucus serratus. Mol Ecol 16:3606-3616.

Hoarau G, Coyer JA, Veldsink JH, Stam WT, Olsen JL. 2007a. Glacial refugia and recolonization pathways in the brown seaweed Fucus serratus. Molecular Ecology 16:3606-3616.

Huerta-Cepas J, Szklarczyk D, Heller D, Hernández-Plaza A, Forslund SK, Cook H, Mende DR, 
Letunic I, Rattei T, Jensen L, et al. 2019. eggNOG 5.0: a hierarchical, functionally and phylogenetically annotated orthology resource based on 5090 organisms and 2502 viruses. Nucleic Acids Res 47:D309-D314.

Huylmans AK, Macon A, Vicoso B. 2017. Global Dosage Compensation Is Ubiquitous in Lepidoptera, but Counteracted by the Masculinization of the Z Chromosome. Mol Biol Evol 34:2637-2649.

Ingleby FC, Flis I, Morrow EH. 2014. Sex-biased gene expression and sexual conflict throughout development. Cold Spring Harb Perspect Biol 7:a017632.

Janicke T, Häderer IK, Lajeunesse MJ, Anthes N. 2016. Darwinian sex roles confirmed across the animal kingdom. Science Advances 2:e1500983.

Katoh K, Misawa K, Kuma K, Miyata T. 2002. MAFFT: a novel method for rapid multiple sequence alignment based on fast Fourier transform. Nucleic Acids Research 30:3059-3066.

Kekäläinen J, Evans JP. 2018. Gamete-mediated mate choice: towards a more inclusive view of sexual selection. Proc Biol Sci [Internet] 285. Available from: https://www.ncbi.nlm.nih.gov/pmc/articles/PMC6083266/

Kirkpatrick M, Hall DW. 2004. Male-biased mutation, sex linkage, and the rate of adaptive evolution. Evolution 58:437-440.

Kokko H, Jennions MD. 2008. Parental investment, sexual selection and sex ratios. Journal of Evolutionary Biology 21:919-948.

Li W, Jaroszewski L, Godzik A. 2001. Clustering of highly homologous sequences to reduce the size of large protein databases. Bioinformatics 17:282-283.

Liao L, Liu J, Dai Y, Li Q, Xie M, Chen Q, Yin H, Qiu G, Liu X. 2009. Development and application of SCAR markers for sex identification in the dioecious species Ginkgo biloba L. Euphytica 169:49-55.

Lipinska A, Cormier A, Luthringer R, Peters AF, Corre E, Gachon CMM, Cock JM, Coelho SM. 2015. Sexual Dimorphism and the Evolution of Sex-Biased Gene Expression in the Brown Alga Ectocarpus. Mol Biol Evol:msv049.

Love MI, Huber W, Anders S. 2014. Moderated estimation of fold change and dispersion for RNA-seq data with DESeq2. Genome Biology 15:550.

Luthringer R, Cormier A, Ahmed S, Peters AF, Cock JM, Coelho SM. 2014. Sexual dimorphism in the brown algae. Perspectives in Phycology 1:11-25.

Madeira F, Park YM, Lee J, Buso N, Gur T, Madhusoodanan N, Basutkar P, Tivey ARN, Potter SC, Finn RD, et al. 2019. The EMBL-EBI search and sequence analysis tools APIs in 2019. Nucleic Acids Res 47:W636-W641.

Magnusson K, Mendes AM, Windbichler N, Papathanos P-A, Nolan T, Dottorini T, Rizzi E, Christophides GK, Crisanti A. 2011. Transcription Regulation of Sex-Biased Genes during Ontogeny in the Malaria Vector Anopheles gambiae. PLoS ONE 6:e21572. 
Mank JE. 2017. The transcriptional architecture of phenotypic dimorphism. Nat Ecol Evol 1:6.

Mank JE, Ellegren H. 2009. Are sex-biased genes more dispensable? Biol Lett 5:409-412.

Mank JE, Hultin-Rosenberg L, Axelsson E, Ellegren H. 2007. Rapid Evolution of Female-Biased, but Not Male-Biased, Genes Expressed in the Avian Brain. Molecular Biology and Evolution 24:2698-2706.

Mank JE, Vicoso B, Berlin S, Charlesworth B. 2010. Effective Population Size and the Faster-X Effect: Empirical Results and Their Interpretation. Evolution 64:663-674.

Martins MJF, Mota CF, Pearson GA. 2013. Sex-biased gene expression in the brown alga Fucus vesiculosus. BMC Genomics 14:294.

Meiklejohn CD, Parsch J, Ranz JM, Hartl DL. 2003. Rapid evolution of male-biased gene expression in Drosophila. PNAS 100:9894-9899.

Meisel RP. 2011. Towards a More Nuanced Understanding of the Relationship between SexBiased Gene Expression and Rates of Protein-Coding Sequence Evolution. Molecular Biology and Evolution 28:1893-1900.

Meisel RP, Malone JH, Clark AG. 2012. Faster-X Evolution of Gene Expression in Drosophila. PLOS Genetics 8:e1003013.

Monteiro C, Heinrich S, Bartsch I, Valentin K, Corre E, Collén J, Harms L, Glöckner G, Bischof K. 2019. Temperature Modulates Sex-Biased Gene Expression in the Gametophytes of the Kelp Saccharina latissima. Front. Mar. Sci. [Internet] 6. Available from: https:// www.frontiersin.org/articles/10.3389/fmars.2019.00769/full

Müller DG, Gaschet E, Godfroy O, Gueno J, Cossard G, Kunert M, Peters AF, Westermeier R, Boland W, Cock JM, et al. A partially sex-reversed giant kelp sheds light into the mechanisms of sexual differentiation in a UV sexual system. New Phytologist [Internet] n/a. Available from: https://nph.onlinelibrary.wiley.com/doi/abs/10.1111/ nph.17582

Müller DG, Gassmann G. 1985. Sexual reproduction and the role of sperm attractants in monoecious species of the brown algae order fucales (fucus, hesperophycus, pelvetia, and pelvetiopsis). J Plant Physiol 118:401-408.

Müller DG, Gassmann G, Lüning K. 1979. Isolation of a spermatozoid-releasing and attracting substance from female gametophytes of Laminaria digitata. Nature 279:430-431.

Naqvi S, Godfrey AK, Hughes JF, Goodheart ML, Mitchell RN, Page DC. 2019. Conservation, acquisition, and functional impact of sex-biased gene expression in mammals. Science [Internet] 365. Available from: https://science.sciencemag.org/content/365/6450/eaaw7317

Papa F, Windbichler N, Waterhouse RM, Cagnetti A, D'Amato R, Persampieri T, Lawniczak MKN, Nolan T, Papathanos PA. 2017. Rapid evolution of female-biased genes among four species of Anopheles malaria mosquitoes. Genome Res 27:1536-1548. 
Parisi M, Nuttall R, Naiman D, Bouffard G, Malley J, Andrews J, Eastman S, Oliver B. 2003. Paucity of Genes on the Drosophila X Chromosome Showing Male-Biased Expression. Science 299:697-700.

Parker GA. 1979. SEXUAL SELECTION AND SEXUAL CONFLICT. In: Blum MS, Blum NA, editors. Sexual Selection and Reproductive Competition in Insects. Academic Press. p. 123166. Available from: https://www.sciencedirect.com/science/article/pii/B9780121087500500100

Parsch J, Ellegren H. 2013. The evolutionary causes and consequences of sex-biased gene expression. Nat Rev Genet 14:83-87.

Pearson G, Lago-Leston A, Valente M, Serrão E. 2006. Simple and rapid RNA extraction from freeze-dried tissue of brown algae and seagrasses. European Journal of Phycology 41:97-104.

Pearson GA, Brawley SH. 1996. Reproductive ecology of Fucus distichus (Phaeophyceae): an intertidal alga with successful external fertilization. Marine Ecology Progress Series 143:211-223.

Pereira V, Waxman D, Eyre-Walker A. 2009. A problem with the correlation coefficient as a measure of gene expression divergence. Genetics 183:1597-1600.

Perry JC, Harrison PW, Mank JE. 2014. The ontogeny and evolution of sex-biased gene expression in Drosophila melanogaster. Mol. Biol. Evol. 31:1206-1219.

Pointer MA, Harrison PW, Wright AE, Mank JE. 2013. Masculinization of Gene Expression Is Associated with Exaggeration of Male Sexual Dimorphism. PLoS Genet 9:e1003697.

Ranz JM, Castillo-Davis Cl, Meiklejohn CD, Hartl DL. 2003. Sex-Dependent Gene Expression and Evolution of the Drosophila Transcriptome. Science 300:1742-1745.

RICE W. 1998. Intergenomic conflict, interlocus antagonistic coevolution, and the evolution of reproduction isolation. Endless forms:261-270.

Schärer L, Rowe L, Arnqvist G. 2012. Anisogamy, chance and the evolution of sex roles. Trends in Ecology \& Evolution 27:260-264.

Scharmann M, Rebelo AG, Pannell JR. 2021. High rates of evolution preceded shifts to sexbiased gene expression in Leucadendron, the most sexually dimorphic angiosperms. bioRxiv:2021.01.12.426328.

Serrão EA, Alice LA, Brawley SH. 1999. EVOLUTION OF THE FUCACEAE (PHAEOPHYCEAE) INFERRED FROM nrDNA-ITS. Journal of Phycology 35:382-394.

Serrão EA, Kautsky L, Lifvergren T, Brawley SH. 1997. Gamete dispersal and pre-recruitment mortality in Baltic Fucus vesiculosus. Phycol. Suppl 36:101-102.

Serrao EA, Pearson G, Kautsky L, Brawley SH. 1996. Successful external fertilization in turbulent environments. PNAS 93:5286-5290.

Silberfeld T, Leigh JW, Verbruggen H, Cruaud C, de Reviers B, Rousseau F. 2010. A multi-locus 
time-calibrated phylogeny of the brown algae (Heterokonta, Ochrophyta, Phaeophyceae): Investigating the evolutionary nature of the "brown algal crown radiation." Molecular Phylogenetics and Evolution 56:659-674.

Song H, Zhang Q, Tian P, Nan Z. 2017. Differential evolutionary patterns and expression levels between sex-specific and somatic tissue-specific genes in peanut. Scientific Reports 7:9016.

Suyama M, Torrents D, Bork P. 2006. PAL2NAL: robust conversion of protein sequence alignments into the corresponding codon alignments. Nucl. Acids Res. 34:W609W612.

Thoemke K, Yi W, Ross JM, Kim S, Reinke V, Zarkower D. 2005. Genome-wide analysis of sexenriched gene expression during C. elegans larval development. Dev Biol 284:500508.

Tirosh I, Barkai N. 2008. Evolution of gene sequence and gene expression are not correlated in yeast. Trends Genet 24:109-113.

Voolstra C, Tautz D, Farbrother P, Eichinger L, Harr B. 2007. Contrasting evolution of expression differences in the testis between species and subspecies of the house mouse. Genome Res 17:42-49.

Wallace AL, Klein AS, Mathieson AC. 2004. Determining the Affinities of Salt Marsh Fucoids Using MicrosaTeLlite Markers: Evidence of Hybridization and Introgression Between Two Species of Fucus (phaeophyta) in a Maine Estuary1. Journal of Phycology 40:1013-1027.

Waterhouse RM, Seppey M, Simão FA, Manni M, loannidis P, Klioutchnikov G, Kriventseva EV, Zdobnov EM. 2018. BUSCO Applications from Quality Assessments to Gene Prediction and Phylogenomics. Mol Biol Evol 35:543-548.

Wray GA. 2007. The evolutionary significance of cis-regulatory mutations. Nat Rev Genet 8:206-216.

Yang L, Zhang Z, He S. 2016. Both Male-Biased and Female-Biased Genes Evolve Faster in Fish Genomes. Genome Biol Evol 8:3433-3445.

Yang X, Schadt EE, Wang S, Wang H, Arnold AP, Ingram-Drake L, Drake TA, Lusis AJ. 2006. Tissue-specific expression and regulation of sexually dimorphic genes in mice. Genome Res 16:995-1004.

Yang Z. 2007. PAML 4: Phylogenetic Analysis by Maximum Likelihood. Mol Biol Evol 24:15861591.

Ye N, Zhang X, Miao M, Fan X, Zheng Y, Xu D, Wang J, Zhou L, Wang D, Gao Y, et al. 2015. Saccharina genomes provide novel insight into kelp biology. Nature Communications 6:1-11.

Zemp N, Tavares R, Muyle A, Charlesworth D, Marais GAB, Widmer A. 2016. Evolution of sexbiased gene expression in a dioecious plant. Nature Plants 2:1-7. 
bioRxiv preprint doi: https://doi org/10.1101/202108 12 455804; this version posted August 15, 2021. The copyright holder for this preprint (which was not certified by peer review) is the author/funder, who has granted bioRxiv a license to display the preprint in perpetuity. It is made available under aCC-BY-NC-ND 4.0 International license.

Zha X, Xia Q, Duan J, Wang C, He N, Xiang Z. 2009. Dosage analysis of Z chromosome genes using microarray in silkworm, Bombyx mori. Insect Biochem Mol Biol 39:315-321.

Zhang Y, Sturgill D, Parisi M, Kumar S, Oliver B. 2007. Constraint and turnover in sex-biased gene expression in the genus Drosophila. Nature 450:233-237.

Zhang Z, Hambuch TM, Parsch J. 2004a. Molecular evolution of sex-biased genes in Drosophila. Mol. Biol. Evol. 21:2130-2139.

Zhang Z, Hambuch TM, Parsch J. 2004b. Molecular evolution of sex-biased genes in Drosophila. Mol Biol Evol 21:2130-2139. 